\title{
Morphologically Distinct Classes of Relay Cells Exhibit Regional Preferences in the Dorsal Lateral Geniculate Nucleus of the Mouse
}

\author{
Thomas E. Krahe, ${ }^{\star}$ Rana N. El-Danaf,* Emily K. Dilger, Scott C. Henderson, and William Guido \\ Department of Anatomy and Neurobiology, Virginia Commonwealth University Medical Center, Richmond, Virginia 23298
}

\begin{abstract}
A fundamental feature of the mammalian visual system is the presence of separate channels that work in parallel to efficiently extract and analyze specific elements of a visual scene. Despite the extensive use of the mouse as a model system, it is not clear whether such parallel organization extends beyond the retina to subcortical structures, such as the dorsal lateral geniculate (dLGN) of thalamus. To begin to address this, we examined the morphology of biocytin-filled relay cells recorded in dLGN of mice. Based on a quantitative assessment of their dendritic architecture, we found that even at early postnatal ages relay cells could be readily classified as X-like (biconical), Y-like (symmetrical), or W-like (hemispheric) and that each cell type was regionally specified in dLGN. X-like cells were confined primarily to the monocular ventral region of dLGN. Y-like cells occupied a central core that also contained ipsilateral eye projections, whereas W-like cells were found along the perimeter of dLGN. Similar to cat, Y-like cells were more prevalent than X-and W-like cells, and X-like cells tended to be smaller than other cell types. However, the dendritic fields of X-and W-like cells did not exhibit an orientation bias with respect to optic tract or boundaries of dLGN. Although we found clear morphological differences among relay cells, an analysis of their electrophysiological properties did not reveal any additional distinguishing characteristics. Overall, these data coupled with recent observations in the retina suggest that the mouse has many of the hallmark features of a system-wide parallel organization.
\end{abstract}

\section{Introduction}

The visual system of many mammals consists of separate parallel pathways that are designed to analyze different aspects of the visual scene (Lennie, 1980; Stone, 1983; Nassi and Callaway, 2009). The discovery of such organization has relied heavily on anatomical and electrophysiological descriptions, but an understanding of the molecular mechanisms underlying their specification and assembly remains unresolved.

However, the advent of mouse models, which delineate genetically encoded markers for specific cell types, has created a wealth of opportunity to explore such avenues (Gong et al., 2007; Rotolo et al., 2008; Badea et al., 2009; Siegert et al., 2009). For example, in the retina, several classes of retinal ganglion cells (RGCs) have been identified, and many of these seem to comprise separate channels that have distinct molecular, morphological, and functional features, as well as unique patterns of connectivity and central projections (Hattar et al., 2006; Huberman et al., 2008,

Received Aug. 25, 2011; revised 0ct. 5, 2011; accepted Oct. 8, 2011.

Author contributions: T.E.K., R.N.E.-D., and W.G. designed research; T.E.K., R.N.E.-D., E.K.D., and W.G. performed research; S.C.H. contributed unpublished reagents/analytic tools; T.K., R.N.E.-D., and E.K.D. analyzed data; T.K., R.N.E.-D., and W.G. wrote the paper.

This work was supported by NIH Grant EY012716 (W.G.). Confocal reconstructions were performed at the Virginia Commonwealth University Department of Anatomy and Neurobiology Microscopy Facility supported in part from NIH/NINDS Center Core Grant 5P30NS047463.

${ }^{*}$ T.E.K. and R.N.E.-D. contributed equally to this work.

Correspondence should be addressed to William Guido, Department of Anatomy and Neurobiology, Virginia Commonwealth University Medical Center, Sanger Hall, 1101 East Marshall Street, Richmond, VA 23298. E-mail: wguido@vcu.edu.

DOI:10.1523/JNEUROSCI.4370-11.2011

Copyright $\odot 2011$ the authors $\quad 0270-6474 / 11 / 3117437-12 \$ 15.00 / 0$
2009; Kim et al., 2008, 2010; Yonehara et al., 2008; Siegert et al., 2009; Ecker et al., 2010; Hong et al., 2011; Kay et al., 2011; RivlinEtzion et al., 2011). Nonetheless, what remains unexplored in the mouse is whether these separate retinal channels are preserved and recapitulated in a parallel manner onto recipient cells in central target structures. For instance, in the dorsal lateral geniculate nucleus (dLGN) of many mammals, at least three different classes of dLGN relay cells have been identified (Stone, 1983; Nassi and Callaway, 2009). Perhaps the most extensively studied have been X-, Y-, and W-cells of the cat (Sherman and Spear, 1982; Sherman, 1985). These cell types are morphologically and functionally distinct, receive information from analogous classes of RGCs, and exhibit strong regional preferences within dLGN. Although there is some evidence for a similar organizational scheme in the rat (Reese, 1988), it is not clear whether mouse thalamocortical cells are functionally or even morphologically distinct (Grubb and Thompson, 2003; Jaubert-Miazza et al., 2005). In fact, it is not even known whether different classes of relay cells exist and, if so, where they reside or when during development they are specified.

To begin to address these issues, and as a prelude to understanding the bases of the morphological diversity of dLGN cells, we examined the dendritic architecture of relay cells at different postnatal ages in a commonly used pigmented strain (C57BL/6) of the mouse. We made use of an acute thalamic slice preparation in which individual cells were filled with biocytin during wholecell recordings and then reconstructed using confocal microscopy. By applying a quantitative assessment of their dendritic orientation and tracking the location of filled cells with respect to 
the boundaries of dLGN as well as eye-specific domains within it, we were able to assess whether morphologically distinct classes of cells resided in discrete locations of dLGN.

\section{Materials and Methods}

Animals. C57BL/6 mice between postnatal day 1 (P1) to P40 were used. Pups were bred in a resident colony from breeders that were obtained from commercial vendors. For all surgical procedures, animals were deeply anesthetized with isoflurane vapors. All experiments were conducted under the guidelines of the Institutional Animal Care and Use Committee at Virginia Commonwealth University.

Slice physiology, intracellular filling, and tissue preparation. To visualize eye-specific domains and the boundaries of dLGN during the recording, we first made intravitreal injections of the anterograde tracer cholera toxin B subunit (CTB; $3-5 \mu \mathrm{l}$ of $1.0 \%$ solution dissolved in distilled water) conjugated to Alexa Fluor 488 or 555 (Invitrogen). After a 24-48 $\mathrm{h}$ survival period, mice were prepared for acute in vitro thalamic slice recordings (Bickford et al., 2010). Because these mice were part of another study that involved the examination of synaptic responses, we adopted a modified sagittal slice preparation that retained retinal axonal input and intrinsic circuitry of dLGN (Chen and Regehr, 2000; Bickford et al., 2010). Typically, we were able to generate two slices through the dorsal thalamus that contained a relatively complete section of dLGN. To confirm our initial findings regarding the regional preferences of identified cell types, additional experiments were conducted in a coronal slice preparation.

Individual (250-300 $\mu \mathrm{m}$ thick) slices containing dLGN were placed into a recording chamber maintained at $32^{\circ} \mathrm{C}$ and perfused continuously at a rate of $2.0 \mathrm{ml} / \mathrm{min}$ with oxygenated ACSF (in mM): $124 \mathrm{NaCl}, 2.5 \mathrm{KCl}$, $1.25 \mathrm{NaH}_{2} \mathrm{PO}_{4}, 2.0 \mathrm{MgSO}_{4}, 26 \mathrm{NaHCO}_{3}, 10$ glucose, and $2 \mathrm{CaCl}_{2}$ (saturated with $95 \% \mathrm{O}_{2} / 5 \% \mathrm{CO}_{2}$ ), $\mathrm{pH}$ 7.4. In vitro intracellular recordings were done in the whole-cell current-clamp configuration with the aid of infrared differential interference contrast (DIC) and fluorescence optics (Olympus VX51) on a fixed stage, visualized recording apparatus. Patch electrodes (3-7 M $\Omega$ ) made of borosilicate glass were filled with a 5\% biocytin solution containing (in $\mathrm{mM}$ ): $130 \mathrm{~K}$-gluconate, 10 HEPES, 8 $\mathrm{NaCl}, 2 \mathrm{ATP}-\mathrm{Mg}$, and $0.1 \mathrm{GTP}-\mathrm{Na}, \mathrm{pH}$ 7.25. Once whole-cell recording was established, neurons were filled with biocytin by passing alternating positive and negative current pulses $( \pm 0.5 \mathrm{nA}, 200 \mathrm{~ms})$ through the recording electrode. For some cells, we examined their membrane properties and firing characteristics by recording the voltage responses to intracellular injections of square-wave current pulses $( \pm 0.01 \mathrm{nA}$ steps, $900 \mathrm{~ms}$ duration). At resting membrane levels, current voltage ( $I-V)$ plots were generated by measuring the steady-state voltage response ( 800 $\mathrm{ms})$ evoked by a systematic increase in current step size $(0.01 \mathrm{nA})$ from -0.1 to $+0.1 \mathrm{nA}$. Time constant and input resistance was determined by measuring the rise time and steady-state voltage responses to a $-0.01 \mathrm{nA}$ step.

After recording, slices were fixed overnight with $4 \%$ paraformaldehyde in $0.1 \mathrm{M}$ PBS, pH 7.2, and then incubated for $24 \mathrm{~h}$ in a $0.1 \%$ solution of Alexa Fluor 647 conjugated to streptavidin (Invitrogen) dissolved in PBS with $0.1 \%$ Triton X-100. Slices were washed with PBS and then mounted with ProLong Gold (Invitrogen), cured overnight at room temperature, and stored in a freezer at $-20^{\circ} \mathrm{C}$. Sections were initially visualized and photographed with an upright epifluorescence microscope (Nikon E6000) to select labeled cells that were suitable for confocal laserscanning microscopy. Relay neurons were readily distinguished from interneurons by the appearance of round somata, radially oriented dendritic trees, and axons that exited the dLGN (Parnavelas et al., 1977).

Cellular imaging and reconstruction. Reconstructions were done using a multiphoton/confocal laser-scanning microscope (Carl Zeiss LSM510 NLO Meta). Fluorescence from labeled dLGN neurons was excited using a $633 \mathrm{~nm}$ helium-neon laser, and emission was detected over a range of 651-694 nm. Targeted neurons were imaged with a Plan-Neofluar $40 \times$ (1.3 NA) oil-immersion objective or a C-Apochromat $40 \times(1.2 \mathrm{NA})$ water-immersion objective at a scan resolution of $2048 \times 2048$ pixels. 3 -D datasets, collected through a depth of $20-100 \mu \mathrm{m}$, were compiled from a sequential series of optical slices with a step size through the $z$-axis of $0.48 \mu \mathrm{m}(40 \times, 1.2 \mathrm{NA})$ or $0.5 \mu \mathrm{m}(40 \times, 1.3 \mathrm{NA})$. Z-stack datasets were rendered using Volocity software (Improvision, version 4.3.2). Image stacks were collected in a plane that was parallel to the surface of the slice and were then deconvolved using an iterative restoration technique to reduce signal noise generated from outside the focal plane of interest. Threshold values were set according to signal intensity and background noise. Cells in which it was not possible to obtain a complete reconstruction of their dendritic field (e.g., cut dendrites that exited the slice) or where neighboring cells had overlapping dendritic arbors or where there was an excessively high background attributable to apparent leakage of dye in the surrounding neuropil were excluded from the study.

From 3-D rendered cells and offline software provided by Volocity, we calculated the following morphological parameters: somatic and dendritic surface area, dendritic field, dendritic branch number, and branch order. The location of labeled cells was noted by examining their position with respect to boundaries of dLGN and eye-specific domains, delineated by CTB-labeled retinal projections. Regional preferences were statistically assessed by performing $\chi^{2}$ analyses on the expected and observed frequencies. To confirm the statistical power of $\chi^{2}$ tests, Monte Carlo simulations $(n=1000)$ were run whenever observed frequencies were $<5$.

\section{Results}

A total of 98 relay neurons in mice ranging in age from $\mathrm{P} 1$ to $\mathrm{P} 40$ were filled with biocytin during intracellular recording and then reconstructed using confocal microscopy (Fig. 1). Representative examples are shown in Figure $2 \mathrm{~A}$. Relay cells had type I or class A morphology (Parnavelas et al., 1977) that consists of a thick unbranched axon, relatively large round somata, and multipolar dendritic arbors comprising six to seven primary dendrites. In fact, even cells at early postnatal ages had fairly large somata and complex dendritic trees with a distinct architecture. Nonetheless, we did observe a substantial change in dendritic architecture after the first postnatal week (Fig. $2 \mathrm{~B}, \mathrm{C}$ ). Between P1 and P5, dendritic trees contained $\sim 40$ branches. At these ages, the majority of branching was confined to the second through fourth order, but some neurons displayed branches up to the sixth to eighth order (Fig. 2C). However, as shown in Figure $2 B$, after P7, dendritic complexity showed a significant increase (one-way ANOVA, $F=$ 7.154, Bonferroni's post hoc test, $p<0.01$ for all comparisons) but then stabilized, such that the total number of branches $(80-100)$ and degree of higher-order branching (third to ninth) were similar for cells across a wide range of postnatal ages (P7-P40; Fig. $2 C$ ). In contrast as shown in Figure $2 D$, soma surface area, although somewhat variable, did not show any significant changes with age. Thus, similar to the observations made in the developing rat dLGN (Parnavelas et al., 1977), relay cells in mouse undergo a rapid growth spurt during early postnatal life. By P7, dendritic branching stabilized and profiles took on a highly stereotypic architecture. All subsequent analyses were conducted on cells between ages P7-P40.

To assess whether these dendritic patterns could be quantified and used as a means to distinguish different morphological subtypes of dLGN cells, we used a Sholl ring analysis (Friedlander et al., 1981). For 73 cells, we compiled a $Z$-stack and, on the projection image, placed five concentric rings at equidistant intervals (range, 15-27 $\mu \mathrm{m}$ ) centered on the soma. The radius of the innermost ring (the most proximal from the soma) was based on the breadth of the total dendritic field, so that the outermost ring (the most distal from the soma) encompassed all but the tips of the longest dendrites. The rings were divided into four quadrants $\left(a_{1}, a_{2}\right.$ and $\left.b_{1}, b_{2}\right)$ by passing two lines through the center of the soma at right angles to one another (Fig. $3 A$ ). In studies that use Sholl rings, these axial lines are oriented perpendicular (vertical) and parallel (horizontal) to eye-specific laminar borders within 


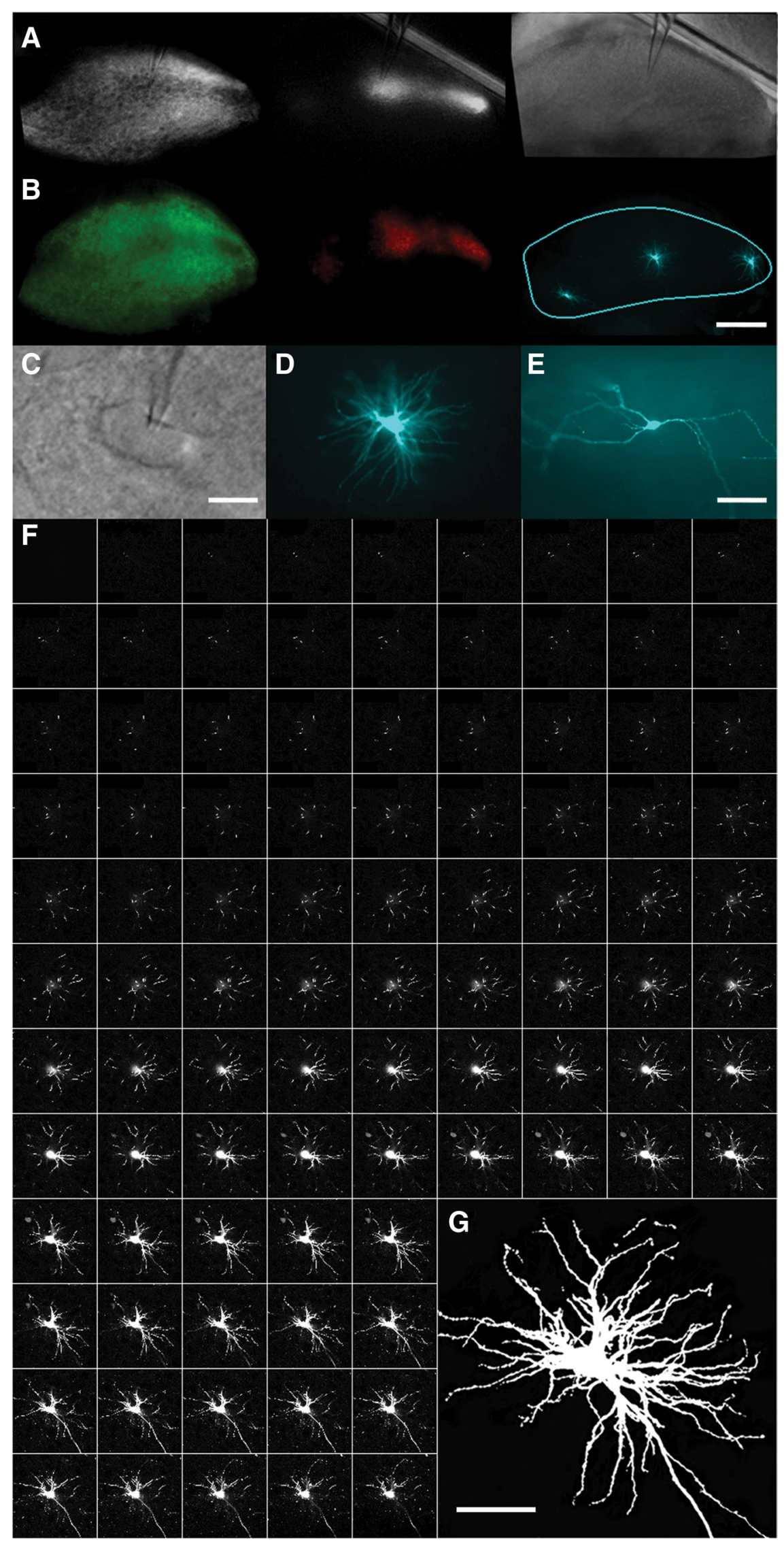

Figure 1. Recording preparation, cellular labeling, and confocal reconstruction of mouse dLGN cells. $A$, Actual fluorescence and DIC images taken through the upright microscope during in vitro slice recording. Left and middle, Anterograde labeling of retina projections with CTB conjugated to Alexa Fluor 488 or 555 . Right, A DIC image of the same slice showing a patch pipette filled with
dLGN (Friedlander et al., 1981; Stanford et al., 1981, 1983). Such positioning ensures that the Sholl ring analysis captures the strong orientation biases in dendritic architecture of some classes of dLGN cells. However, the mouse dLGN lacks such lamination (Jaubert-Miazza et al., 2005). Instead, retinal projections from the ipsilateral eye occupy only $\sim 10-15 \%$ of the nucleus and form an irregularly shaped patch that courses through the anteromedial region. Thus, in keeping with previous strategies (Friedlander et al., 1981; Stanford et al., 1981, 1983), the lines delineating the quadrants of the Sholl rings were arranged to maximize the difference in dendritic intersections between the two axial planes. For a given cell, the number of dendritic intersections passing through each ring was counted and grouped by axial plane $\left(a_{1}+a_{2}\right.$ or $\left.b_{1}+b_{2}\right)$. The ratio of dendritic intersections in one plane versus the other (minimum/maximum) was taken as an index of dendritic orientation (DOi). A DO $i$ of 1.0 represents a cell with equal number of intersections in both axial planes, whereas a cell with intersections in just one plane would have a DO $i$ of 0.0 .

A $k$-means cluster analysis (Hartigan and Wong, 1979; Blashfield and Aldenderfer, 1984) was then conducted to examine the independent grouping of cells by their pattern of dendritic orientation. Because the algorithm requires that $k$, the number of expected clusters, must be specified a priori, we used the "elbow criterion" as a convenient heuristic to estimate the optimal number of clusters, if any (Jain et al., 1999; Chen et al., 2007). Briefly, this criterion is based on the plot of the ratio of the between-group variance to the total variance (total sum of squares) as a function of cluster number (Fig. 3B). As the number of clusters increases, the

$\leftarrow$

biocytin. $\boldsymbol{B}$, Same sections as in $\boldsymbol{A}$ but here the slice is fixed and photographed through an upright epifluorescence microscope. Shown are crossed (left, green) and uncrossed (middle, red) retinal projections along with three biocytin-filled cells (right, pseudocolored in blue but labeled with far-red Alexa Fluor 647). The solid blue line delineates the boundaries of dLGN. Scale bar, $200 \mu \mathrm{m}$. C, Higher magnification of far right panel $\boldsymbol{A}$ showing DIC image of a dLGN relay cell with the tip of the patch pipette. Scale bar, $5 \mu \mathrm{m}$. D, Same relay cell shown in $\boldsymbol{C}$ and ( $\boldsymbol{B}$, far right panel, middle cell) after fixation and streptavidin reaction. $\boldsymbol{A}-\boldsymbol{D}$ are from the same slice taken from a P17 mouse. $\boldsymbol{E}$, Example of a biocytin-labeled interneuron from another dLGN slice of a P14 mouse. Relay cells and interneurons have distinct morphology and can be readily distinguished. Scale bar, $20 \mu \mathrm{m}$. $\boldsymbol{F}$, Confocal sequential series of optical slices of a dLGN neuron (atP15) with a step size through the z-axis of $0.48 \mu \mathrm{m}$. G, Projection image of the 3-D rendered cell shown in $\boldsymbol{F}$. Scale bar, $50 \mu \mathrm{m}$. 

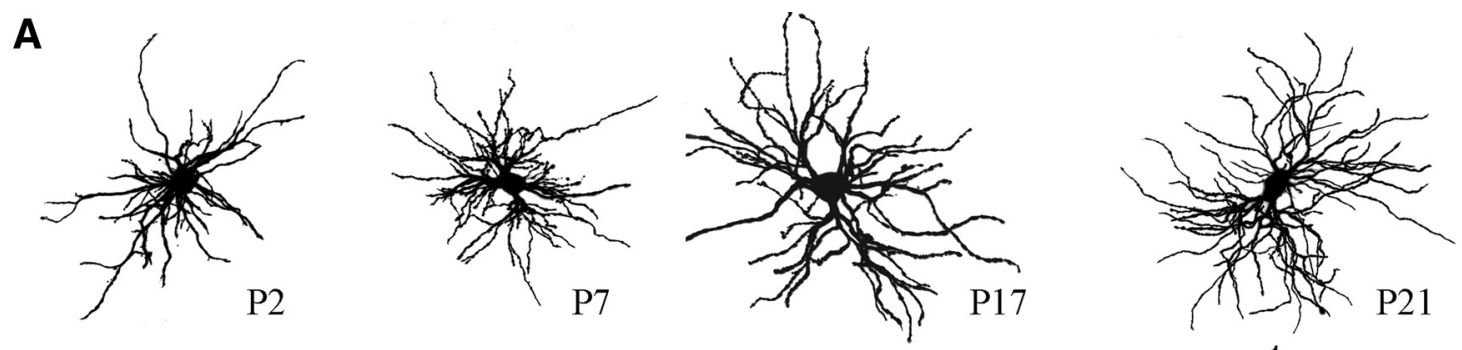

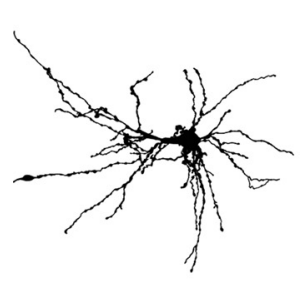

P5

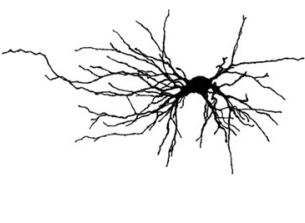

P8

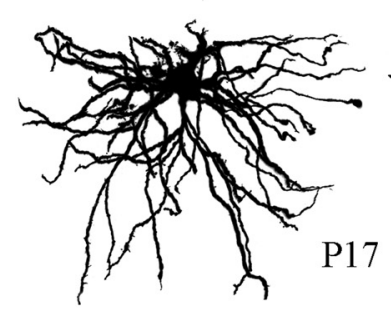

P17

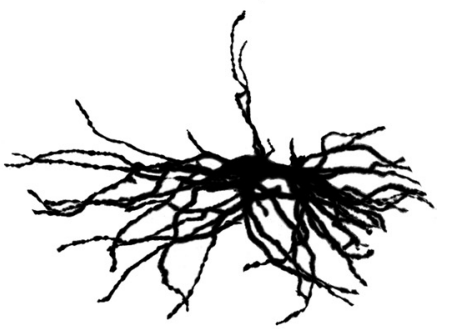

P27

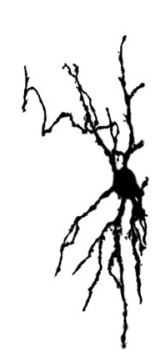

P2

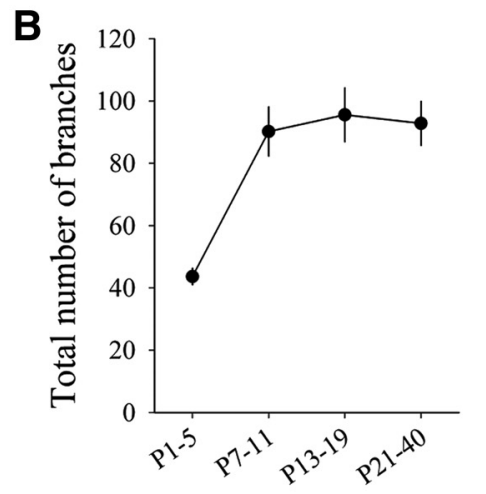

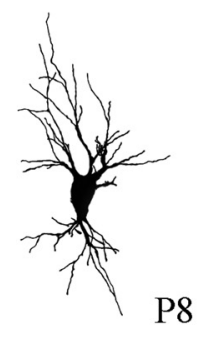

P8
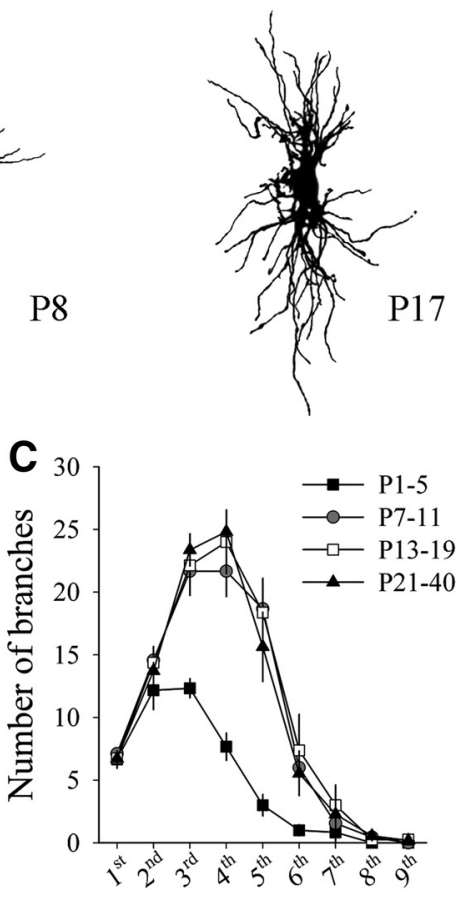

Branch order
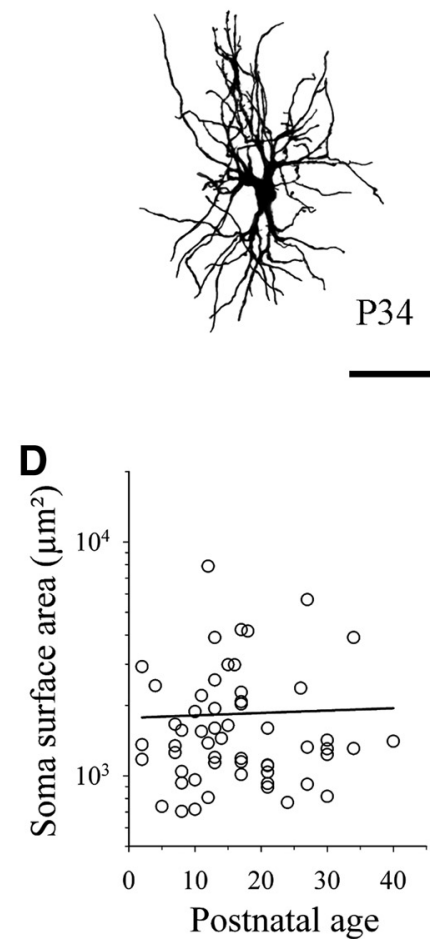

Figure 2. Morphology of developing dLGN relay cells. $A$, Reconstructions are based on the Z-stack images of representative relay neurons filled with biocytin at different postnatal ages. Neurons are grouped by dendritic architecture (top, radially symmetric; middle, hemispherical; bottom, biconical) and arranged within a row by increasing postnatal age (bottom right corner of each cell). Scale bar, $50 \mu \mathrm{m} . \boldsymbol{B}, \boldsymbol{C}$, Summary plots showing the mean number of branches $(\boldsymbol{B})$ and branch order $(\boldsymbol{C})$ at different postnatal ages. At P1-P5, the complexity of relay cells is not fully mature (P1-P5, $n=5$ cells; $P 7-P 11, n=9 ; P 13-P 19, n=7 ; P 21-P 40, n=11)$. Error bars represent SEM. $\boldsymbol{D}$, Scatter plot showing soma cell surface area at different postnatal ages (P1-P40). Each point represents a single neuron $(n=56)$. Linear regression is shown as the best-fit line and did not reveal any correlation between soma size and postnatal age $\left(\mathrm{df}=56, R^{2}=0.0009, p=0.83\right)$.

total variance explained by the data increases monotonically until an additional increase in the number of clusters reaches a plateau. In other words, an inflection in this curve (the "elbow") reflects the number of clusters that account for a substantial fraction of the variance. Beyond this point, adding more clusters does not substantially increase the amount of variance accounted for. Thus, the location of the elbow is used to delineate the appropriate number of clusters within a given dataset. Finally, it should be noted that the absence of an elbow may be an indication that there is no cluster structure in the data.

When these analyses were applied to $\mathrm{DO} i$ values of biocytinfilled cells, three clusters were identified (Fig. 3B). As illustrated in the frequency distribution of DOi values (Fig. 3C), three distinct groups existed. Representative cells from each group are shown in Figure 3D. The group on the far left of the DO $i$ distribution (Fig. 3D, left) represents cells with dendritic intersections that were restricted to only one axial plane, those in the middle of the distribution (Fig. 3D, middle) had values that reflected intersections that were found in one plane and the quadrant of the other, whereas those on the far right (Fig. 3D, right) had an equivalent number of intersections in one axial plane or the other.

To better illustrate the dendritic architecture of cells in each of the three defined groups shown in Figure 3C, we generated polar plots that were based on the outermost dendritic intersections 
A

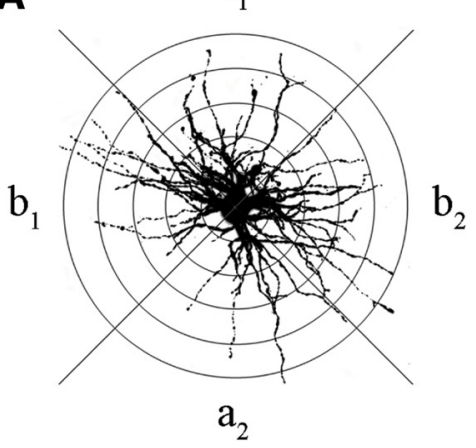

B

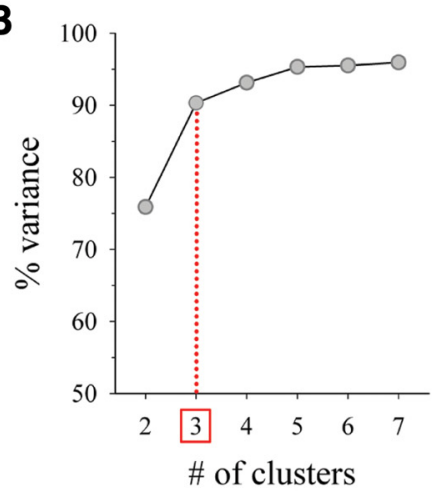

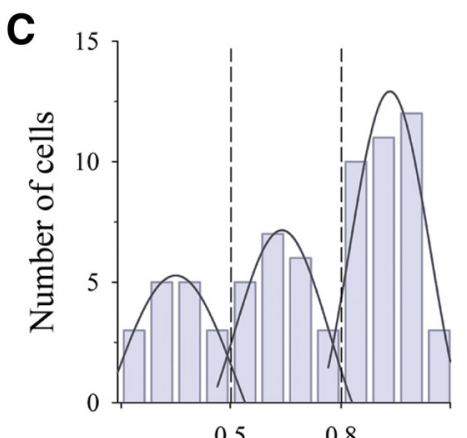

$0.5 \quad 0.8$
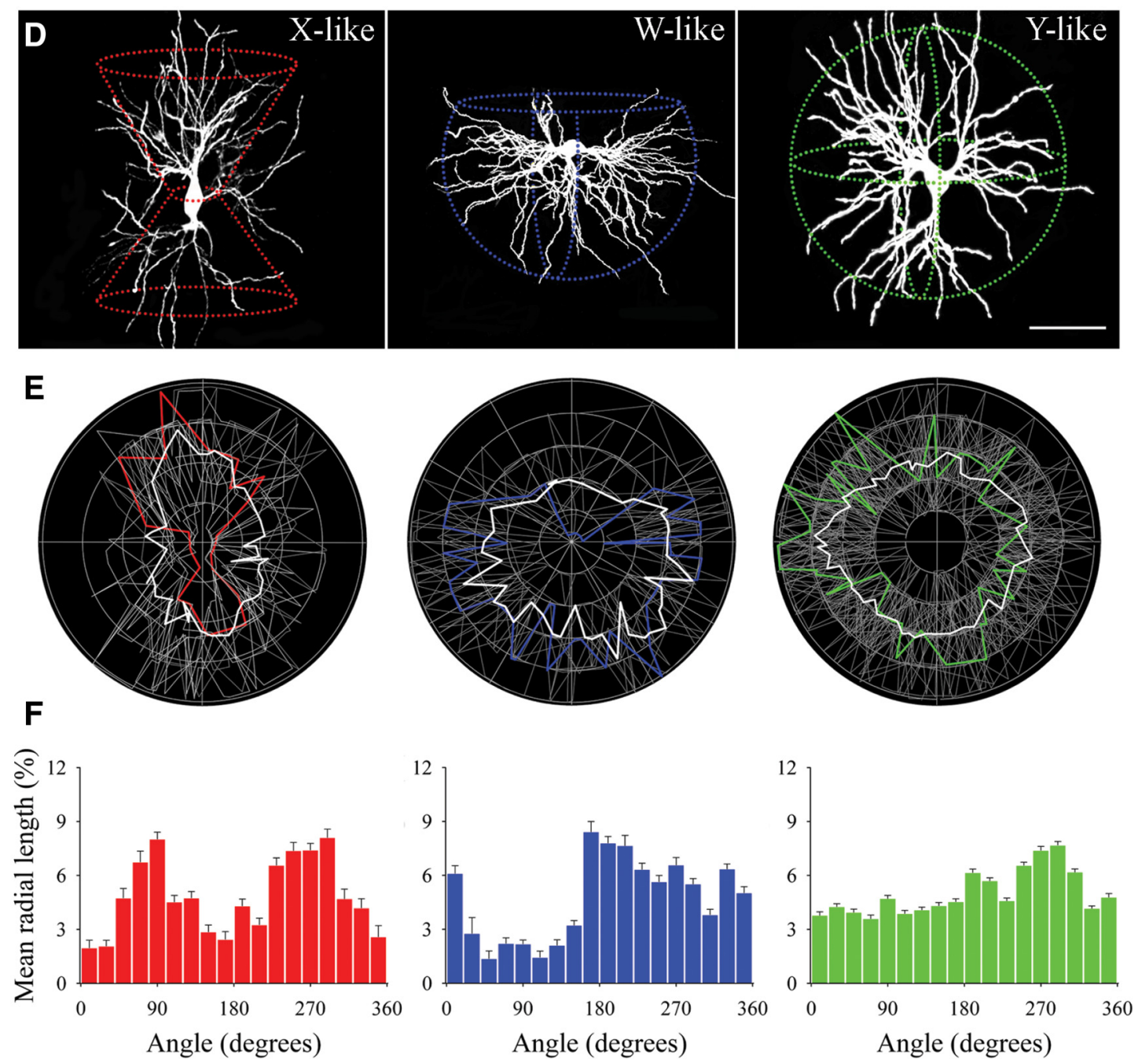

Figure 3. Quantitative assessment of dendritic architecture. $A$, Example of a Sholl ring superimposed on the dendritic tree of a relay cell. The dendritic tree spans across two axial planes and four quadrants $\left(a_{1}, a_{2}\right.$ and $\left.b_{1}, b_{2}\right)$. The concentric rings have equidistant intervals centered on the soma. For each cell, we computed a D0i, the ratio of the minimum/maximum number of intersections in each axial plane $\left(a_{1}+a_{2}\right.$ or $\left.b_{1}+b_{2}\right)$. B , Plot depicts the percentage of variance in the DOivalues for all cells $(n=73)$ as explained by the number of clusters. The percentage of variance explained is the ratio of the between-group variance to the total variance (see Results). The red dotted line delineates the point in the graph (3 clusters) in which an additional increase in the number of clusters does not yield a significant change in the percentage of variance explained. C, Histogram that plots the distribution of DOi values for all cells. Solid lines represent Gaussian fits, and dotted vertical lines delineate the three clusters determined in $\boldsymbol{B}$. The group on the far left $(0-0.49)$ are cells $(n=16)$ with the least amount of intersections in one plane or the other $\left(a_{1}+a_{2}\right.$ or $\left.b_{1}+b_{2}\right)$, the middle group $(0.50-0.79)$ are cells $(n=21)$ that had intersections in one plane and the quadrant of the other, and on the far right $(0.80-1.0)$ are cells $(n=36)$ that had approximately the same number of intersections in one axial plane or the other. $\boldsymbol{D}$, Representative examples of cells in each of the defined groups from $\boldsymbol{B}$ and $\boldsymbol{C}$. Dashed lines illustrate the dendritic architecture. Note that each profile resembles the dendritic architecture of $X-, W$-, and Y- cells of the cat. Scale bar, $50 \mu \mathrm{m}$. E, Superimposed polar plots of the dendritic profiles (thin gray lines) for cells in each of the defined groups as determined by the analyses in $A-C$. Polar plots were generated by using the outermost dendritic intersections and the soma center as the point of origin. For X-like cells, plots were arranged so their biconical shape was oriented vertically; for W-like cells, plots were arranged such that the quadrant with the fewest dendritic branches appeared on top. Colored lines (red, blue, and green) depict the dendritic profiles of $X-, W$-, and Y-like cells shown in $\boldsymbol{D}$. Thick white lines are the median profiles for each group. $\boldsymbol{F}$, Summary histograms of the average radial length of the outermost intersections at different angles depicted in plots shown in $\boldsymbol{E}$. Angles increase in a clockwise manner with $0^{\circ}$ corresponding to the right horizontal axis of plots shown in $\boldsymbol{E}$. Bin size, $22.5^{\circ}$. 
Table 1. Morphological parameters of relay cells from the mouse dLGN

\begin{tabular}{|c|c|c|c|c|c|}
\hline Cell & Dendrite $S A\left(\mu \mathrm{m}^{2}\right) \times 10^{3}$ & Soma $S A\left(\mu \mathrm{m}^{2}\right) \times 10^{3}$ & Age (days) & $\mathrm{DF}\left(\mu \mathrm{m}^{3}\right) \times 10^{6}$ & Age (days) \\
\hline X & $22.92 \pm 3.64[57.74 \pm 9.17]$ & $1.53 \pm 0.17[74.92 \pm 8.42]$ & $17.1 \pm 2.87(12)$ & $1.55 \pm 0.25[63.96 \pm 10.24]$ & $17.4 \pm 2.5(14)$ \\
\hline W & $39.46 \pm 5.92[99.40 \pm 14.90]$ & $2.04 \pm 0.46[100.00 \pm 22.53]$ & $15.9 \pm 1.8(17)$ & $1.95 \pm 0.26[80.37 \pm 10.84]$ & $15.9 \pm 1.7(19)$ \\
\hline Y & $39.70 \pm 5.47[100.00 \pm 13.79]$ & $1.71 \pm 0.20[83.73 \pm 9.66]$ & $18.2 \pm 1.5(27)$ & $2.42 \pm 0.24[100.00 \pm 9.98]$ & $18.5 \pm 1.4(31)$ \\
\hline
\end{tabular}

Data are presented as mean \pm SE. Numbers in brackets are averaged percentages \pm SE, and numbers in parentheses represent number of cells. Percent-wise, X-like cells are significantly smaller than W-and Y-like cells (univariate ANOVA, $F=3.54, p<0.05)$. DF, Dendritic field; SA, surface area. Age values are in postnatal days.

occurring within each one of the rings (Fig. 3E). For each of these intersections, we then measured the radial length and the corresponding angle using the soma center as the point of origin. Summary histograms (Fig. $3 F$ ), which plot these lengths as a function of angle, further underscore the existence of three morphological subtypes. Indeed, each group bears a striking resemblance to X-, Y-, and W-cells of the cat (Friedlander et al., 1981; Stanford et al., 1981, 1983). Cells with X-like morphology had a biconical shape and orientation preferences that were $180^{\circ}$ apart from each other. Cells with W-like morphology had a hemispheric profile with orientation preferences that occupied all but one quadrant. Finally, cells with Y-like morphology had a profile that was radially symmetric and showed no orientation preference in their dendritic tree. The relative proportions of each of these subtypes were significantly different from chance levels $\left(\chi^{2}=11.53\right.$, df $=2, p<0.01$; Y-like, $\left.z=2.77, p<0.01\right)$ and similar to values reported in the cat (Friedlander et al., 1981; Stanford et al., 1981, 1983). From a total of 73 cells, close to half (49\%) were Y-like, 22\% X-like, and 29\% W-like. Moreover, we found that X-like cells tended to be smaller than $\mathrm{W}$ - and Y-like cells. For example, Table 1 reveals that dendritic and soma surface area, as well as the spatial extent of their dendritic fields, was comparatively smaller for X-like cells. Indeed, these differences do not appear related to the postnatal age of cells in each group (one-way ANOVAs, $F=0.406$ for surface area, $F=0.629$ for dendritic field, $p>0.53$ for both comparisons).

In the absence of eye-specific lamination, we instead investigated whether dendritic architecture of X- and W-like cells exhibited a particular orientation bias with respect to the borders of dLGN. Interestingly, unlike the cat (Friedlander et al., 1981; Stanford et al., 1981, 1983), X- and W-like cells in the mouse did not exhibit a particular orientation preference. Figure 4 provides examples of how the dendritic trees of X-and W-like cells were aligned either with respect to optic tract (X-like) or the boundaries of dLGN (W-like). These reference points were chosen based on the strong regional preferences each cell type displayed (see below). For X-like cells, approximately half had their biconical shape arranged perpendicular to the optic tract, whereas the others were aligned in parallel (Fig. $4 C$, left; $\chi^{2}=0.2$, df $=1, p=$ $0.66)$. For $\mathrm{W}$-like cells, just as many were likely to have their hemispheric dendritic profile facing toward as away from the borders of dLGN (Fig. $4 C$, right; $\chi^{2}=0.04$, df $=1, p=0.84$ ). It is important to note that the analysis of $\mathrm{W}$-like cells was restricted to those with a soma that was within $100 \mu \mathrm{m}$ of a border, indicating that the boundaries of the nucleus did not pose as a physical determinant of morphological subtype.

Although we found clear morphological differences among relay cells, an analysis of their active and passive membrane properties showed no additional distinguishing characteristics. For 44 biocytin filled cells (X-like, $n=12$; W-like, $n=10$; Y-like, $n=$ 22 ), we recorded whole-cell voltage responses evoked by intracellular current injection. Figure $5 A$ provides representative examples of voltage responses and $I-V$ relations for each of the identified groups. The active membrane properties and underly- ing voltage-gated conductances of dLGN cells can be readily inferred based on the nonlinearities noted in these voltage responses and $I-V$ curves (Crunelli et al., 1987, 1989; Williams et al., 1996; MacLeod et al., 1997; Ziburkus et al., 2003; JaubertMiazza et al., 2005). Based on these highly stereotypic voltage signatures, it appears that X-, W-, and Y-like cells possessed the full complement of voltage-gated conductances that are typically reported for dLGN relay cells. For example, membrane hyperpolarization activated a mixed cation conductance that led to strong inward rectification (i.e., depolarizing sag). The cessation of hyperpolarizing current steps and passive repolarization of membrane levels evoked large triangular "rebound" low-threshold $\mathrm{Ca}^{2+}$ spikes and burst firing. Membrane depolarization activated an outward rectifying $\mathrm{K}^{+}$conductance, which delayed the onset of spike firing. Finally, strong levels of membrane depolarization produced spike trains that exhibited frequency accommodation. As shown in Figure $5 B$, values of resting membrane potential $\left(V_{\mathrm{m}}\right)$, input resistance $\left(I_{\mathrm{R}}\right)$, and membrane time constant $\left(\tau_{0}\right)$ were also not different among $\mathrm{X}$-, $\mathrm{W}$-, and $\mathrm{Y}$-like cells (one-way ANOVAs, $F=1.031$ for resting $V_{\mathrm{m}}, F=0.532$ for $I_{\mathrm{R}}, F=0.199$ for $\tau_{0}, p>0.36$ for all comparisons).

To examine whether these morphologically defined cell types reside in specific regions of the dLGN, we tracked the location of 61 cells from a total of 36 slices in which they were recorded (Fig. 6). An example of a typical slice along with CTB-labeled terminal fields delineating the boundaries of dLGN and eye-specific domains are shown in Figure $6 \mathrm{~A}$. Because dLGN slices varied in size and shape, we normalized each one with respect to its maximum height and width. Outlines of each slice along with the relative position of filled cells are shown in Figure $6 \mathrm{~B}$. Although cells of each group were not completely segregated within dLGN, clear regional preferences were apparent. For example, the majority of $\mathrm{X}$-like cells were located near the ventroposterior border of $\mathrm{dLGN}$, adjacent to the intergeniculate leaflet (IGL) and ventral lateral geniculate nucleus ( $\mathrm{VLGN}$ ) in a region that corresponds to the monocular segment (Coleman et al., 2009). W-like cells were dispersed along the outer boundaries of dLGN, in regions that lie near the optic tract or the opposing border of the nucleus. Y-like cells were broadly distributed throughout dLGN but were most prevalent within a central band that coursed throughout its length in a plane that was approximately parallel to the optic tract.

To assess these preferences statistically, we divided the cell location plot of Figure $6 B$ into the patterns shown in Figure $6 C$ ( $a-c$, three vertical sectors; $d-f$, three horizontal sectors; and $g, h$, inner and outer sectors). We then compared the observed and expected frequencies for a given cell type within each of these sectors (Fig. 6C). X-like cells showed a significant regional preference in sectors $a, e$, and $h$ primarily because of the clustering noted in the monocular segment $\left(a-c: \chi^{2}=12.40, \mathrm{df}=2, p<\right.$ 0.01, Monte Carlo 0.1\%; $a: z=2.68, p<0.01 ; d-f: \chi^{2}=19.6, \mathrm{df}=$ $2, p<0.0001$, Monte Carlo 0.0\%; $e: z=4.32, p<0.0001 ; g$, $h$ : $\chi^{2}=4.26, \mathrm{df}=1, p<0.05$, Monte Carlo 2.7\%). W-like cells exhibited a significant preference for sector $h$, which corresponds 
A
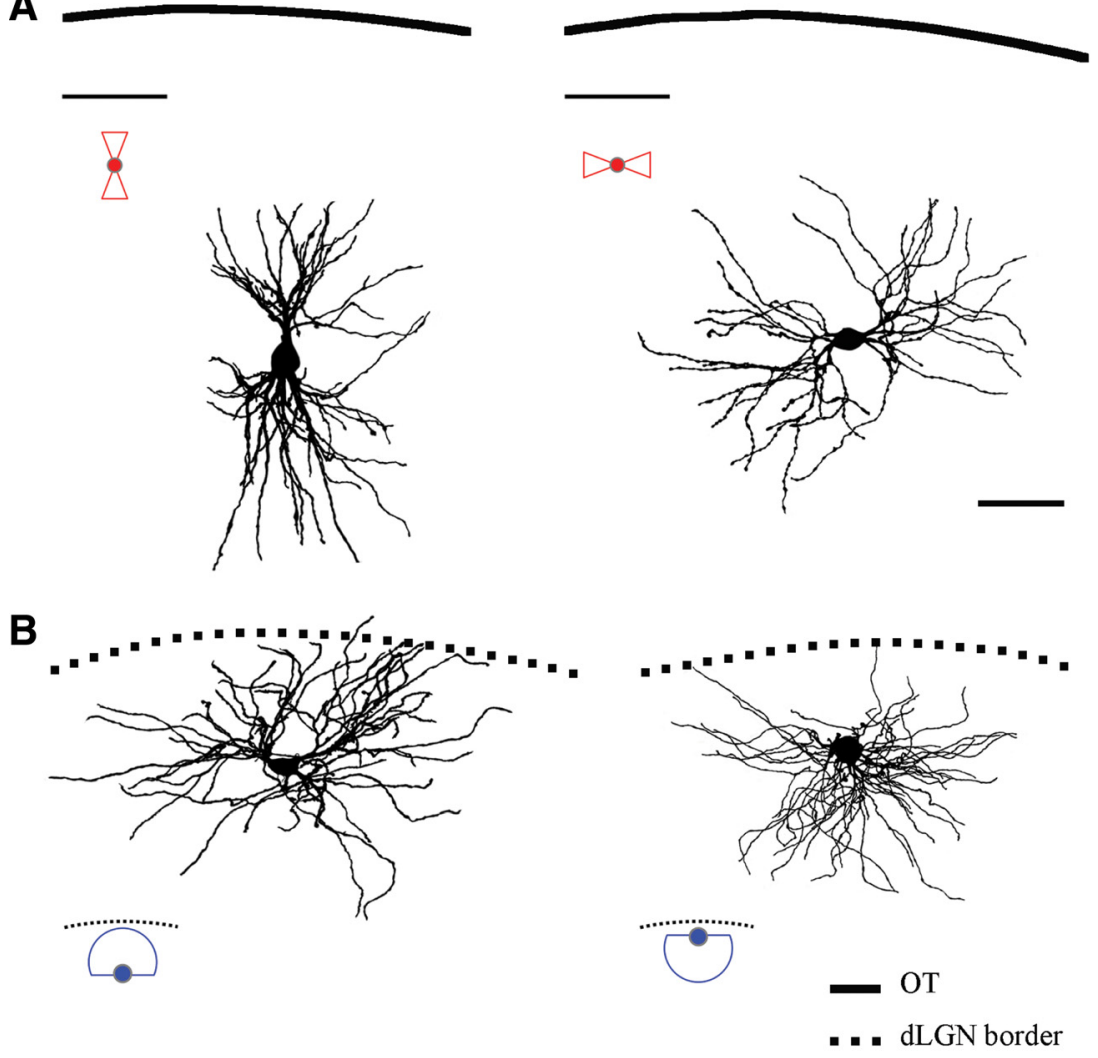

C
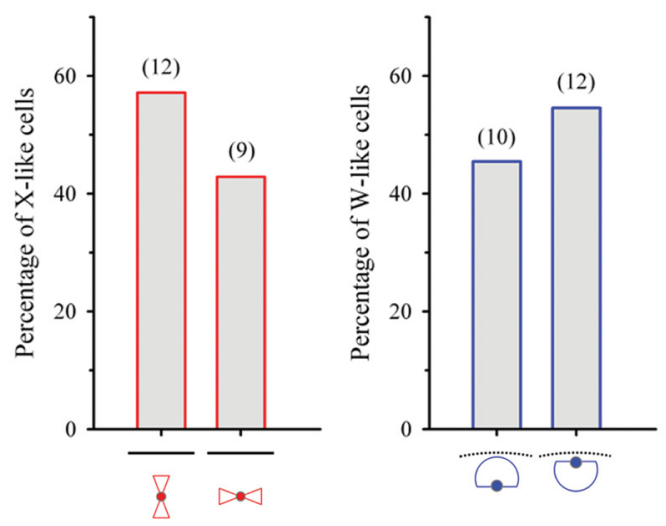

Figure 4. Pattern of dendritic orientation for X-and W-like cells. $A, B$, Representative reconstructions of X-and W-like cells in relation to the optic tract (OT) or boundaries of dLGN. For X-like cells, dendritic orientation was examined relative to the optic tract (perpendicular or parallel, solid line). For W-like cells, orientation was examined relative to the boundaries of the dLGN (dendritic arbor away or toward, dotted line). Reconstructions are based on the Z-stack images of relay neurons filled with biocytin. Schematic drawings depict dendritic orientation for X-like (red) and W-like (blue) cells (dLGN border, dotted line; optic tract, solid line). Scale bar, $50 \mu \mathrm{m}$. C, Bar graphs showing the orientation preferences for X-and W-like cells. For the latter, those cells that had their soma within $100 \mu \mathrm{m}$ from dLGN border were included (22 of 28). Numbers in parentheses depict cell counts. Schematic drawings are the same as in $\boldsymbol{A}$ and $\boldsymbol{B}$.

to the perimeter of dLGN ( $g, h: \chi^{2}=5.06, \mathrm{df}=1, p<0.05$, Monte Carlo 1.7\%). Y-like cells showed a significant preference for sector $e$, which corresponds to a central strip within dLGN $\left(d-f: \chi^{2}=10.94, \mathrm{df}=2, p<0.01\right.$, Monte Carlo 0.5\%; $e: z=2.71$, $p<0.01)$. Typically, this region was occupied by projections arising from the ipsilateral eye (Fig. 6A). Indeed, as shown in Figure 7 , in slices in which the eye-specific domains were labeled with CTB, we found that 11 of 15 cells $(73 \%)$ that had their soma within this region were Y-like $\left(\chi^{2}=12.88, \mathrm{df}=2, p<0.01\right.$, Monte Carlo 0.1\%; Y-like, $z=2.89, p<0.01)$. Moreover, similar to the arrangement of Y-cells in the cat (Friedlander et al., 1981), for many Y-like cells in mouse, their dendritic fields extended beyond the boundaries of the ipsilateral eye into regions occupied by contralateral eye terminal fields. Finally, as shown in Figure $6 D$, the regional preferences noted above were also apparent in thalamic slices cut in the coronal plane (21 slices, $n=31$ cells; $a, b$ : X-like, $\chi^{2}=4.16, \mathrm{df}=1, p<0.05$, Monte Carlo 3.5\%; W-like, $\chi^{2}=8.64$, df $=1, p<$ 0.01 , Monte Carlo 0.1\%; Y-like, $\chi^{2}=$ $0.00, \mathrm{df}=1, p=1.0$ ).

To better illustrate the spatial relations of identified cell types, we generated summary diagrams (Fig. 8) that incorporated cell locations from slices cut in the parasagittal and coronal plane. Overall, X-like cells resided in the monocular segment of dLGN near the ventral border separating dLGN from IGL. W-like cells seemed to form a ring around the perimeter of dLGN. In fact, for most $(79 \%, 22 / 28)$ their soma was located within $100 \mu \mathrm{m}$ of the boundaries of the nucleus $\left(\chi^{2}=8.04\right.$, $\mathrm{df}=1, p<0.01)$. Finally Y-like cells were more evenly dispersed throughout a central core of dLGN, and, compared with Xand $\mathrm{W}$-like cells, they showed a strong preference for the binocular region of dLGN (Caviness et al., 1980; Coleman et al., 2009).

\section{Discussion}

A key element of parallel pathway organization is the presence of separate cell types at all levels of processing. Although such organization is readily apparent in carnivores and primates, it is unclear whether the mouse has separate channels that remain segregated beyond the retina. Here we report that relay cells in the mouse dLGN are morphologically distinct and have dendritic architecture that closely resembles X-, Y-, and $\mathrm{W}$-cells of the cat. Moreover, these cell types showed regional preferences within dLGN, with $\mathrm{Y}$ - and X-like cells displaying an anteriorto-posterior gradient and W-like cells surrounding the perimeter of dLGN. In fact, these regional preferences are consistent with studies done in the rat, suggesting that the rodent $\mathrm{dLGN}$ is organized into two separate domains; a rostroventral central core comprised of cells that receive input primarily from fast-conducting, large, type I RGCs, and an outer caudodorsal shell comprised of cells that receive input from slowly conducting, smaller type II and III RGCs (Reese, 1988). Additional anatomical evidence seems to support the presence of a third domain, located in the posterodorsal region (i.e., monocular segment) that serves as a recipient zone for subset of smaller type II and III RGCs (Martin, 1986).

Thus, our results in the mouse add to the growing list of evidence in support of a system-wide parallel organization for the 
rodent. Nonetheless, it is important to consider them in the context of the following unresolved issues. First, although morphologically distinct, are relay cells in the mouse functionally distinct? Second, do the regional preferences of mouse relay cells in dLGN correspond to the reported axon terminal domains for different subtypes of RGCs? Finally, are mouse relay cells positioned to serve as a parallel conduit of information for certain regions of visual cortex? Each of these questions is considered below.

In the mouse, it remains unclear whether morphologically defined subtypes of relay cells possess different functional properties. Indeed, an analysis of their membrane properties did not reveal any obvious differences, a trend that has also been noted in the rat and cat (Sherman and Koch, 1986; Crunelli et al., 1987, 1989; Soltesz et al., 1989; Williams et al., 1996; Ziburkus et al., 2003). Moreover, what little evidence there is on the structure-function relations of mouse dLGN cells suggests that the receptive field properties of mouse dLGN cells are known more for their homogeneity rather than their diversity (Grubb and Thompson, 2003, 2005). In general, mouse dLGN cells display a centersurround organization (on-center or off-center) and linear spatial summation. Most notable is the lack of nonlinear spatial summation, because the latter is a distinguishing characteristic of Y-cells recorded in the cat (Friedlander et al., 1981). Instead, in this regard, the mouse dLGN seems more like the primate. In the latter, all cells, including M-cells, the homolog of Y-cells, show linear spatial summation (Derrington and Lennie, 1984; Usrey and Reid, 2000). Also noteworthy is the reported absence of direction selectivity in mouse dLGN, because this is a defining feature for a number of identified RGC types that form lamina-like projection domains, especially in the dorsolateral tier of dLGN (Kim et al., 2008; Huberman et al., 2009; Kim et al., 2010; Rivlin-Etzion et al., 2011). However, until these regions have been properly sampled during in vivo recordings, the possibility still exists that relay cells located here may in fact exhibit some form of direction selectivity. Perhaps, as suggested by Huberman et al. (2009), mouse dLGN cells are more broadly tuned for direction selectivity and receive convergent input from more than one type of direction-selective RGC.

Although morphologically distinct groups of mouse relay cells showed strong regional preferences in dLGN, they do not seem positioned to serve as an exclusive recipient zone for any one class of RGCs. For example, we found that Y-like cells occupy a central core in $\mathrm{dLGN}$, a region that serves as the primary terminal domain for transient Off- $\alpha$-cells and a group of On/Off
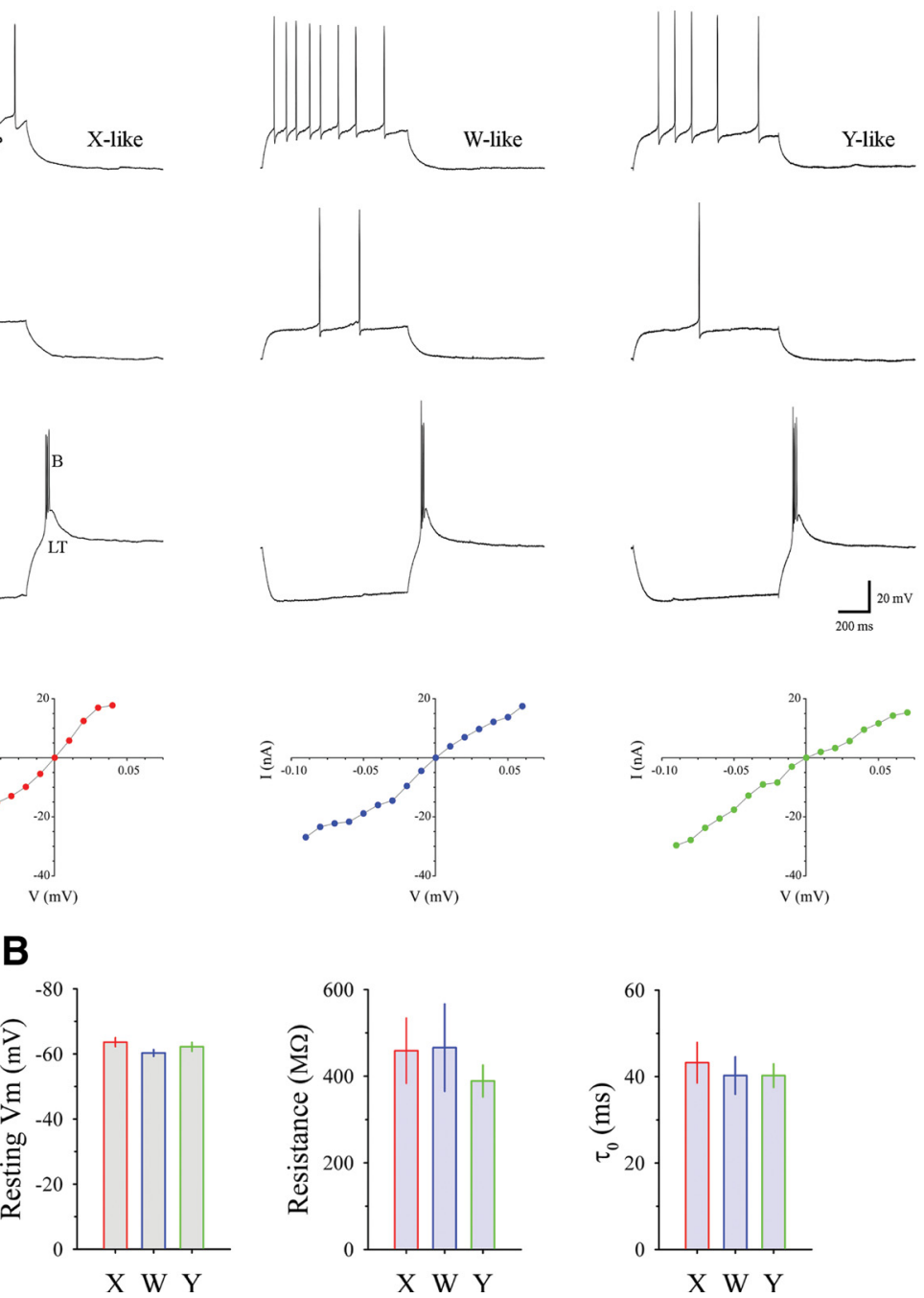

Figure 5. Membrane properties of morphologically identified cells types in dLGN. $A$, Representative examples of voltage ( $V$ responses to current ( $($ ) injections for a X-like (left column, P14), W-like (middle column, P24), and Y-like (right column, P17) cell. lots below traces depict the corresponding I $-V$ relations for each cell ( $\pm 0.01 \mathrm{nA}$ square-wave current pulses; $900 \mathrm{~ms}$ long). Note accommodation (AHP) during membrane depolarization. Corresponding $I-V$ plots depict similar forms of inward and outward rectification. $\boldsymbol{B}$, Bar graphs showing the averages for resting membrane potenti
$(n=12)$, W-like $(n=10)$, and Y-like $(n=22)$ cells. Error bars represent SEM.

direction-selective cells that responds to posterior motion $(\mathrm{Hu}-$ berman et al., 2008; Kim et al., 2010, 2011). These RGC types also terminate in ventromedial regions of dLGN, an area in which some W-like cells were located. Additionally, we found that X-like cells that showed perhaps the strongest regional preference residing almost exclusively in the ventroposterior region of dLGN just dorsal to IGL seem to represent just a small portion of much larger terminal domains for several indentified RGC types that vary both in morphology and receptive field structure (Hattar et al., 2006; Huberman et al., 2008, 2009; Kim et al., 2008, 2010; Badea et al., 2009; Siegert et al., 2009; Ecker et al., 2010; Kay et al., 2011). Indeed, such overlap between RGC projections and the spatial preferences of dLGN cells is to be expected given the wide diversity of RGC types (Masland, 2001). Perhaps, a more likely scenario is one in which multiple classes of RGCs that either share a common property or are broadly tuned for one converge onto a specific cell type in dLGN. Most notable in this regard may 
A

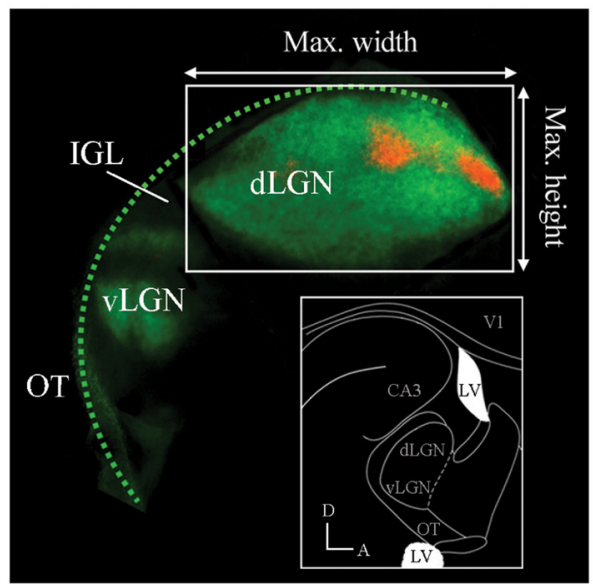

C

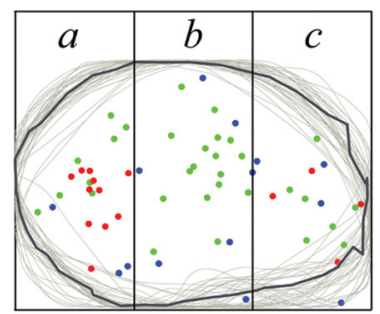

$\begin{array}{lll}a & b & c\end{array}$

$\mathrm{X} 11(73) * 0(00) 4(27)$

$\mathrm{W} 3(21) \quad 6(43) 5(36)$

Y 8(25) 17 (53) 7 (22)

$\mathrm{E}_{\text {fireq }} \quad \frac{1}{3}(33.3) \quad \frac{1}{3}(33.3) \frac{1}{3}(33.3)$

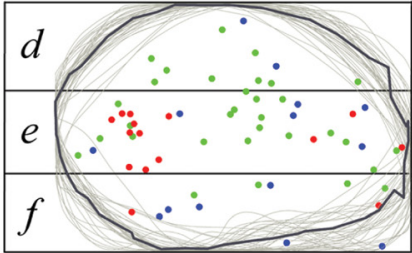

d e f

$0(00) \quad 13(87) * 2(13)$

2 (14) $6(43) \quad 6(43)$

9 (28) $19(59) * 4(13)$

$\frac{1}{3}(33.3) \quad \frac{1}{3}(33.3) \quad \frac{1}{3}(33.3)$

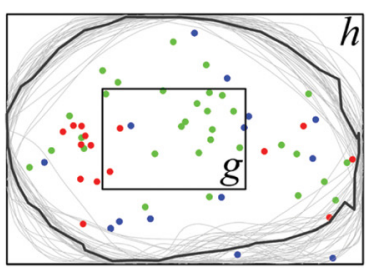

g h

2 (13) $13(87)^{*}$

$2(20) \quad 12(80)^{*}$

14 (44) $18(56)$

$\frac{1}{2}(50) \quad \frac{1}{2}(50)$

D

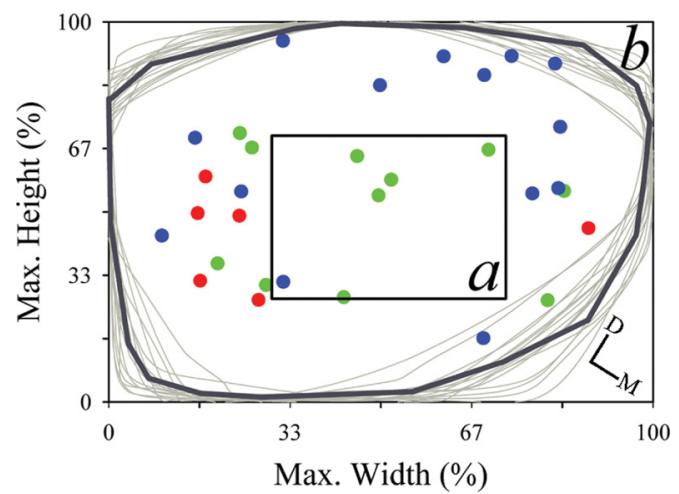

Figure 6. Location of identified cell types in dLGN. A, An example of (TB-filled section of dLGN, showing crossed (green) and uncrossed (red) retinal projections. Adjacent to the optic tract (OT) is the IGL and VLGN. For purposes of orientation, a schematic of a sagittal section through the dorsal thalamus is provided (D, dorsal; $A$, anterior; CA3, field of hippocampus; V1, primary visual cortex; LV, lateral ventricle). $\boldsymbol{B}$, Outlines of dLGN slices ( $n=36$, thin gray lines) along with the relative position of each identified cell type (colored symbols: X-like, red, $n=15 ; \mathrm{W}$-like, blue, $n=14$; and $Y$-like, green, $n=32$ ). Outlines and cell location have been normalized with respect to maximum height and width of dLGN $(\boldsymbol{A})$. Thick black line reflects the median of all outlines. $\boldsymbol{C}$, Cell location was assessed by dividing dLGN plot of $\boldsymbol{B}$ into the following sectors: $\boldsymbol{a}-\boldsymbol{c}$, three vertical sectors; $\boldsymbol{d}-\boldsymbol{f}$, three horizontal sectors; $\boldsymbol{g}, \boldsymbol{h}$, inner and outer sectors. Below each pattern are the corresponding observed (number of cells and corresponding percentages in parentheses) and expected frequencies $\left(E_{\text {freq }}\right)$ for a given cell type. Locations showing a significant spatial preference for a given cell type are marked with an asterisk (all $p$ values $<0.01$ to 0.05 ). D, Outlines of dLGN slices $(n=21)$ cut in the coronal plane along with the relative position of 31 identified cell types. All other conventions are the same as $\boldsymbol{B}$. D, Dorsal; $\mathrm{M}$, medial. For $\boldsymbol{B}$ and $\boldsymbol{D}$, a total of 18 cells were classified qualitatively (X-like, $n=5 ; \mathrm{W}$-like, $n=7 ; \mathrm{Y}$-like, $n=6$ ).

be the location of a subset of W-like cells that occupied a dorsolateral strip adjacent to the optic tract. This area, also known as the dorsal lateral shell, is distinct from other regions of dLGN because it contains a high concentration of calbindin-positive cells and serves as the recipient zone for the collilculo-geniculate projection (Reese, 1984; Grubb and Thompson, 2004). This region shares a similar homology to the tecto-recipient zones noted in the C-laminae of carnivores (Demeulemeester et al., 1991) and the koniocellular division of some primates (Harting et al., 1991). At least three classes of identified direction-selective RGCs project to this area: a group of Off cells that respond to upward motion (Kim et al., 2008, 2010) and two groups of On/Off cells that prefer posterior motion (Huberman et al., 2009; RivlinEtzion et al., 2011). Interestingly, these cell types also project to 


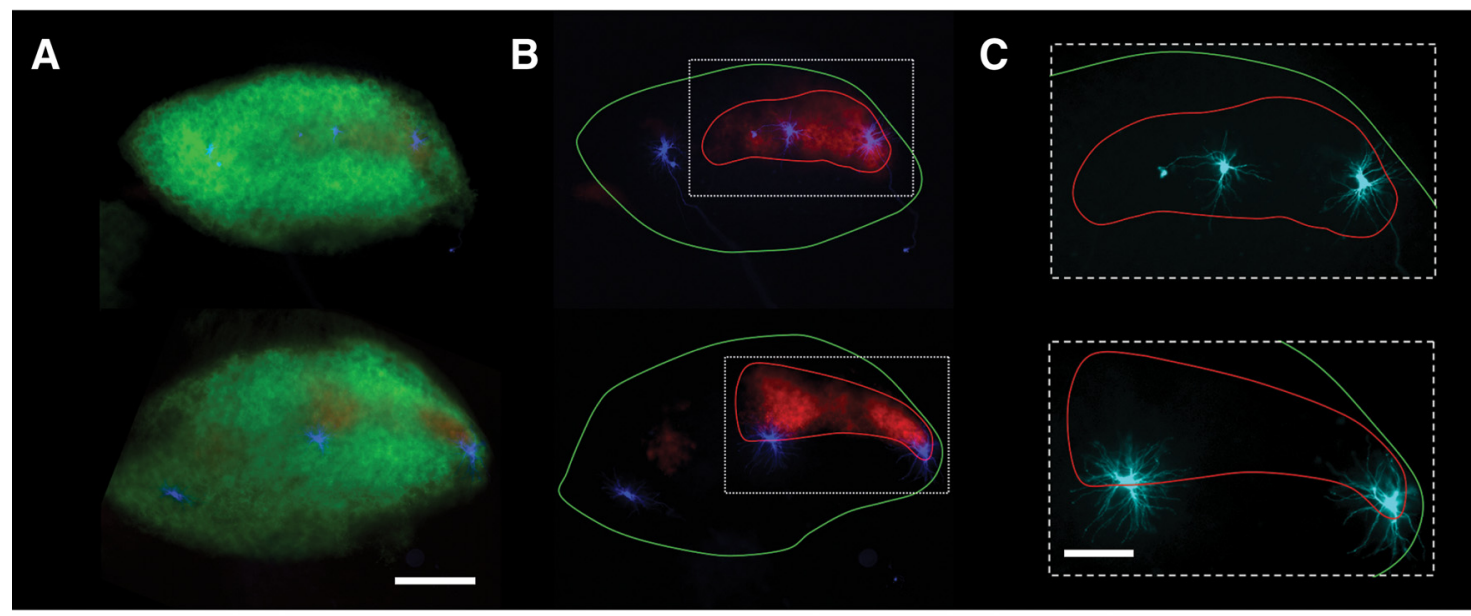

D
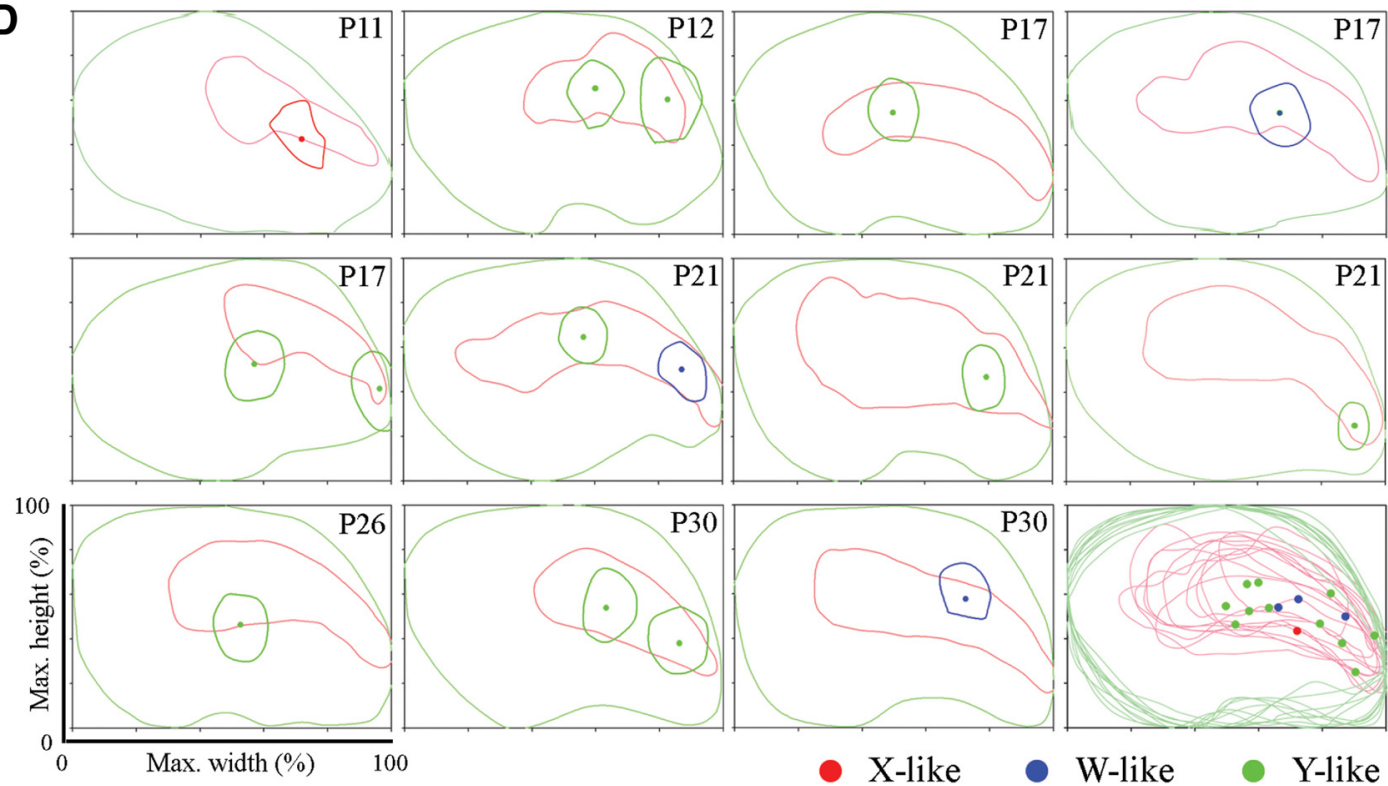

Figure 7. Location of identified cell types relative to eye-specific domains in dLGN.A-C, Panels illustrate representative CTB-filled sections of dLGN taken from a P12 (top row) and P17 mouse (bottom row). $\boldsymbol{A}, \boldsymbol{B}$, Crossed projections are shown in green $(\boldsymbol{A})$ and uncrossed ones from the same section in red ( $\boldsymbol{B})$. $\boldsymbol{C}$, Higher magnifications of insets in $\boldsymbol{B}$ depict relay cells located within (top) or on the border (bottom) of the uncrossed retinal projections region (red lines). Biocytin filled relay cells in $A$-Care in blue. Scale bars: $A, B, 200 \mu \mathrm{m} ; C, 100 \mu \mathrm{m}$. D, Outlines of normalized dLGN slices $(n=11)$ containing cells located inside or near the borders of uncrossed retinal projections. Green lines represent the boundaries of dLGN and red lines the domains of uncrossed retinal projections. Filled circles represent cell soma location and the line around them the corresponding dendritic field. Bottom right depicts all dLGN outlines and cell somas. The majority of cells (11 of 15) located in or near the ipsilateral eye terminal domain are Y-like. Note also that, in several cases, dendritic fields extend beyond the boundaries into regions innervated by the contralateral eye.

superior colliculus and thus may be part of a unique colliculo-geniculate feedback loop that involves information conveyed by these RGC types. Thus, a major challenge of future experiments is to delineate the pattern of retinal convergence that exists between and within different groups of dLGN cells.

Finally, it is important to consider how the regional specification of identified cell types in dLGN relates to the functional organization of visual cortex. Most notable was the discovery that X-like cells resided primarily within the monocular portion of dLGN, whereas Y-like cells were in the binocular segment. Such apparent segregation has important functional implications because thalamocortical afferents
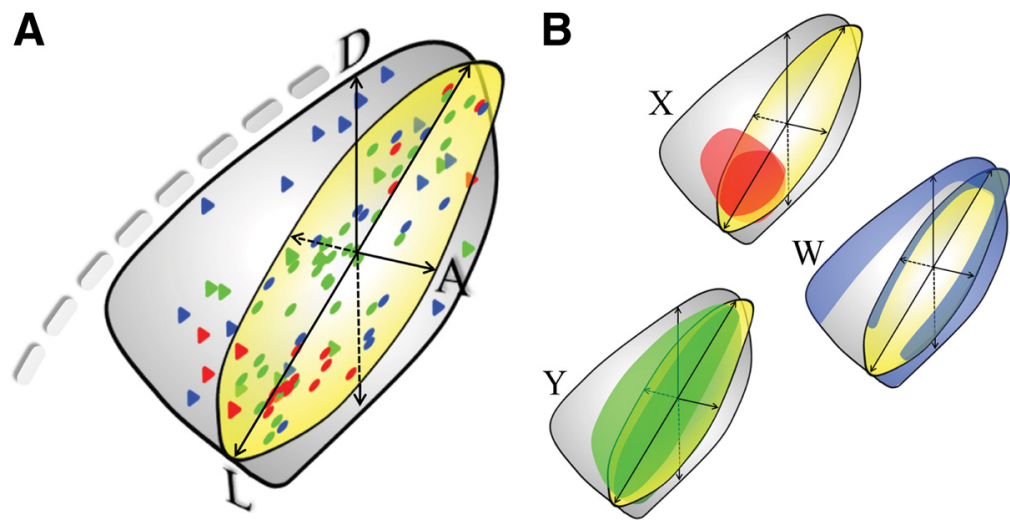

Figure 8. Summary diagrams showing the regional preferences of different cell types in $\operatorname{dLGN}$. $A$, Drawing illustrating the relative position of X-like (red), W-like (blue), and Y-like (green) cells in parasagittal (filled circles; see Fig. 5B) and coronal (filled triangles; see Fig. 5D) planes of dLGN. Both planes were intersected and rotated to provide a 3-D rendering of the dLGN. A, Anterior; $D$, dorsal; L, lateral. $B$, Similar diagrams to $\boldsymbol{A}$ where each color highlights the preferred location of each cell type in the dLGN. 
from these regions project in parallel to monocular and binocular regions of visual cortex (Caviness and Frost, 1980; Coleman et al., 2009). Although the response properties of visual cortical neurons show some evidence of parallel channels especially in the spatiotemporal domain (Gao et al., 2010), it remains unclear how such organization relates to monocular and binocular regions of primary visual cortex $\mathrm{V} 1$ or to the reported homogeneity of dLGN receptive field properties.

In summary, our experiments provide a potential substrate for parallel organization in the mouse visual system and pave the way for future studies to explore how functional cell class specificity originating in the retina is recapitulated in $\mathrm{dLGN}$ and then relayed to visual cortex.

\section{References}

Badea TC, Cahill H, Ecker J, Hattar S, Nathans J (2009) Distinct roles of transcription factors brn3a and brn $3 b$ in controlling the development, morphology, and function of retinal ganglion cells. Neuron 61:852-864.

Bickford ME, Slusarczyk A, Dilger EK, Krahe TE, Kucuk C, Guido W (2010) Synaptic development of the mouse dorsal lateral geniculate nucleus. J Comp Neurol 518:622-635.

Blashfield RK, Aldenderfer MS (1984) Cluster analysis. Newbury Park, CA: Sage.

Caviness VS Jr, Frost DO (1980) Tangential organization of thalamic projections to the neocortex in the mouse. J Comp Neurol 194:335-367.

Chen C, Regehr WG (2000) Developmental remodeling of the retinogeniculate synapse. Neuron 28:955-966.

Chen F, El-Dawlatly S, Jin R, Oweiss (2007) Identifying and tracking the number of independent clusters of functionally interdependent neurons from biophysical models of population activity. Presented at the Third International IEEE/EMBS Conference on Neural Engineering, Kohala Coast, HI, May 2-5.

Coleman JE, Law K, Bear MF (2009) Anatomical origins of ocular dominance in mouse primary visual cortex. Neuroscience 161:561-571.

Crunelli V, Leresche N, Parnavelas JG (1987) Membrane properties of morphologically identified $\mathrm{X}$ and $\mathrm{Y}$ cells in the lateral geniculate nucleus of the cat in vitro. J Physiol 390:243-256.

Crunelli V, Lightowler S, Pollard CE (1989) A T-type $\mathrm{Ca}^{2+}$ current underlies low-threshold $\mathrm{Ca}^{2+}$ potentials in cells of the cat and rat lateral geniculate nucleus. J Physiol 413:543-561.

Demeulemeester H, Arckens L, Vandesande F, Orban GA, Heizmann CW, Pochet R (1991) Calcium binding proteins as molecular markers for cat geniculate neurons. Exp Brain Res 83:513-520.

Derrington AM, Lennie P (1984) Spatial and temporal contrast sensitivities of neurones in lateral geniculate nucleus of macaque. J Physiol 357:219-240.

Ecker JL, Dumitrescu ON, Wong KY, Alam NM, Chen SK, LeGates T, Renna JM, Prusky GT, Berson DM, Hattar S (2010) Melanopsin-expressing retinal ganglion-cell photoreceptors: cellular diversity and role in pattern vision. Neuron 67:49-60.

Friedlander MJ, Lin CS, Stanford LR, Sherman SM (1981) Morphology of functionally identified neurons in lateral geniculate nucleus of the cat. J Neurophysiol 46:80-129.

Gao E, DeAngelis GC, Burkhalter A (2010) Parallel input channels to mouse primary visual cortex. J Neurosci 30:5912-5926.

Gong S, Doughty M, Harbaugh CR, Cummins A, Hatten ME, Heintz N, Gerfen CR (2007) Targeting Cre recombinase to specific neuron populations with bacterial artificial chromosome constructs. J Neurosci 27:9817-9823.

Grubb MS, Thompson ID (2003) Quantitative characterization of visual response properties in the mouse dorsal lateral geniculate nucleus. J Neurophysiol 90:3594-3607.

Grubb MS, Thompson ID (2004) Biochemical and anatomical subdivision of the dorsal lateral geniculate nucleus in normal mice and in mice lacking the beta2 subunit of the nicotinic acetylcholine receptor. Vision Res 44:3365-3376.

Grubb MS, Thompson ID (2005) Visual response properties of burst and tonic firing in the mouse dorsal lateral geniculate nucleus. J Neurophysiol 93:3224-3247.
Hartigan JA, Wong MA (1979) Algorithm AS: A K-means clustering algorithm. J R Stat Soc Ser C Appl Stat 28:100-108.

Harting JK, Huerta MF, Hashikawa T, van Lieshout DP (1991) Projection of the mammalian superior colliculus upon the dorsal lateral geniculate nucleus: organization of tectogeniculate pathways in nineteen species. J Comp Neurol 304:275-306.

Hattar S, Kumar M, Park A, Tong P, Tung J, Yau KW, Berson DM (2006) Central projections of melanopsin-expressing retinal ganglion cells in the mouse. J Comp Neurol 497:326-349.

Hong YK, Kim IJ, Sanes JR (2011) Stereotyped axonal arbors of retinal ganglion cell subsets in the mouse superior colliculus. J Comp Neurol 519:1691-1711.

Huberman AD, Manu M, Koch SM, Susman MW, Lutz AB, Ullian EM, Baccus SA, Barres BA (2008) Architecture and activity-mediated refinement of axonal projections from a mosaic of genetically identified retinal ganglion cells. Neuron 59:425-438.

Huberman AD, Wei W, Elstrott J, Stafford BK, Feller MB, Barres BA (2009) Genetic identification of an on-off direction-selective retinal ganglion cell subtype reveals a layer-specific subcortical map of posterior motion. Neuron 62:327-334.

Jain AK, Murty MN, Flynn PJ (1999) Data clustering: a review. ACM Comput Surveys 31:264-323.

Jaubert-Miazza L, Green E, Lo FS, Bui K, Mills J, Guido W (2005) Structural and functional composition of the developing retinogeniculate pathway in the mouse. Vis Neurosci 22:661-676.

Kay JN, De la Huerta I, Kim IJ, Zhang Y, Yamagata M, Chu MW, Meister M, Sanes JR (2011) Retinal ganglion cells with distinct directional preferences differ in molecular identity, structure, and central projections. J Neurosci 31:7753-7762.

Kim IJ, Zhang Y, Yamagata M, Meister M, Sanes JR (2008) Molecular identification of a retinal cell type that responds to upward motion. Nature 452:478-482.

Kim IJ, Zhang Y, Meister M, Sanes JR (2010) Laminar restriction of retinal ganglion cell dendrites and axons: subtype-specific developmental patterns revealed with transgenic markers. J Neurosci 30:1452-1462.

Lennie P (1980) Parallel visual pathways: a review. Vision Res 20:561-594.

MacLeod N, Turner C, Edgar J (1997) Properties of developing lateral geniculate neurones in the mouse. Int J Dev Neurosci 15:205-224.

Martin PR (1986) The projection of different retinal ganglion cell classes to the dorsal lateral geniculate nucleus in the hooded rat. Exp Brain Res 62:77-88.

Masland RH (2001) The fundamental plan of the retina. Nat Neurosci 4:877-886.

Nassi JJ, Callaway EM (2009) Parallel processing strategies of the primate visual system. Nat Rev Neurosci 10:360-372.

Parnavelas JG, Mounty EJ, Bradford R, Lieberman AR (1977) The postnatal development of neurons in the dorsal lateral geniculate nucleus of the rat: a golgi study. J Comp Neurol 171:481-499.

Reese BE (1984) The projection from the superior colliculus to the dorsal lateral geniculate nucleus in the rat. Brain Res 305:162-168.

Reese BE (1988) "Hidden lamination" in the dorsal lateral geniculate nucleus: the functional organization of this thalamic region in the rat. Brain Res 472:119-137.

Rivlin-Etzion M, Zhou K, Wei W, Elstrott J, Nguyen PL, Barres BA, Huberman AD, Feller MB (2011) Transgenic mice reveal unexpected diversity of on-off direction-selective retinal ganglion cell subtypes and brain structures involved in motion processing. J Neurosci $31: 8760-8769$.

Rotolo T, Smallwood PM, Williams J, Nathans J (2008) Geneticallydirected, cell type-specific sparse labeling for the analysis of neuronal morphology. PLoS One 3:e4099.

Sherman SM (1985) Functional organization of the W-, X-, and Y-cell pathways: a review and hypothesis. In: Progress in psychobiology and physiological psychology (Sprague JM, Epstein AN, eds), pp 233-314. New York: Academic.

Sherman SM, Koch C (1986) The control of retinogeniculate transmission in the mammalian lateral geniculate nucleus. Exp Brain Res 63:1-20.

Sherman SM, Spear PD (1982) Organization of visual pathways in normal and visually deprived cats. Physiol Rev 62:738-855.

Siegert S, Scherf BG, Del Punta K, Didkovsky N, Heintz N, Roska B (2009) Genetic address book for retinal cell types. Nat Neurosci 12:1197-1204. 
Soltesz I, Lightowler S, Leresche N, Crunelli V (1989) On the properties and origin of the GABAB inhibitory postsynaptic potential recorded in morphologically identified projection cells of the cat dorsal lateral geniculate nucleus. Neuroscience 33:23-33.

Stanford LR, Friedlander MJ, Sherman SM (1981) Morphology of physiologically identified W-cells in the Claminae of the cat's lateral geniculate nucleus. J Neurosci 1:578-584.

Stanford LR, Friedlander MJ, Sherman SM (1983) Morphological and physiological properties of geniculate W-cells of the cat: a comparison with Xand Y-cells. J Neurophysiol 50:582-608.

Stone J (1983) Parallel processing in the visual system. New York: Plenum.

Usrey WM, Reid RC (2000) Visual physiology of the lateral geniculate nu- cleus in two species of new world monkey: Saimiri sciureus and Aotus trivirgatis. J Physiol 523:755-769.

Williams SR, Turner JP, Anderson CM, Crunelli V (1996) Electrophysiological and morphological properties of interneurones in the rat dorsal lateral geniculate nucleus in vitro. J Physiol 490:129-147.

Yonehara K, Shintani T, Suzuki R, Sakuta H, Takeuchi Y, NakamuraYonehara K, Noda M (2008) Expression of SPIG1 reveals development of a retinal ganglion cell subtype projecting to the medial terminal nucleus in the mouse. PLoS One 3:e1533.

Ziburkus J, Lo FS, Guido W (2003) Nature of inhibitory postsynaptic activity in developing relay cells of the lateral geniculate nucleus. J Neurophysiol 90:1063-1070. 